\section{Use of Adalimumab in Treatment of Autoimmune Sensorineural Hearing Loss: A Word of Caution}

\section{To the Editor:}

We read with interest the report of Morovic Vergles, et al outlining a case of autoimmune sensorineural hearing loss and rheumatoid arthritis (RA) treated successfully with adalimumab ${ }^{1}$. Infliximab has also been reported to be effective in the treatment of autoimmune sensorineural hearing loss ${ }^{2}$. Etanercept has had contrasting results in this setting, mostly negative ${ }^{3,4}$. We recently encountered 2 cases of sensorineural hearing loss temporally related to adalimumab. These are the first such cases in the literature that we know of. There has been 1 previous account of acquired sensorineural hearing loss in the setting of etanercept usage that was judged unlikely to be related to etanercept ${ }^{5}$. We counsel caution in the usage of anti-tumor necrosis factor (anti-TNF) agents in this setting until further studies are undertaken.

The first case was a 44-year-old woman with a 5-year history of refractory seronegative arthritis who had little response to methotrexate or leflunomide. She had an anaphylactic reaction to infliximab after 1 year of usage. She began taking adalimumab in March 2003. In late 2003 she developed sensorineural hearing loss in her left ear and was reviewed by the otorhinolaryngology service. A magnetic resonance image (MRI) of her brain was normal; specifically, there was no evidence of acoustic neuroma. She was taking concurrent leflunomide treatment. Anti-TNF treatment was stopped; she has had no recovery of hearing and remains deaf in her left ear.

The second case was a 34-year-old woman diagnosed with inflammatory spondyloarthitis. She had a poor response to methotrexate and sulfasalazine. She had an excellent response after taking adalimumab, but developed left-side hearing loss identified after the fifth injection. This was confirmed as unilateral sensorineural hearing loss following otorhinolaryngology review and brain MRI. Adalimumab was stopped; there was no improvement in hearing over the first 2 months following cessation, but over the subsequent 2 months her hearing improved to normal.

Anti-TNF agents may be associated with the development of sensorineural hearing loss. This hearing loss may not be reversible in all cases.
However, autoimmune hearing loss has been reported to occur in association with autoimmune diseases such as $\mathrm{RA}^{1,6}$. The sensorineural hearing loss in our cases may represent cases of autoimmune hearing loss in association with inflammatory arthritis but this is usually bilateral. Clinicians should consider this as a rare cause of unexplained hearing loss in a patient receiving an anti-TNF drug.

RICHARD CONWAY, MD, MRCPI, Rheumatology Specialist Registrar; SULEMAN KHAN, MD, MRCPI, Rheumatology Registrar; DARRAGH FOLEY-NOLAN, MD, FRCPI, Consultant Rheumatologist, Waterford Regional Hospital, Dunmore Road, Waterford, Ireland. Address correspondence to Dr. Conway; E-mail: drrichardconway@gmail.com

\section{REFERENCES}

1. Morovic Vergles J, Radic M, Kovacic J, Salamon L. Successful use of adalimumab for treating rheumatoid arthritis with autoimmune sensorineural hearing loss: two birds with one stone [letter]. J Rheumatol 2010;37:1080-1.

2. Van Wijk F, Staecker H, Keithley E, Lefebvre PP. Local perfusion of the tumor necrosis factor $\alpha$ blocker infliximab to the inner ear improves autoimmune neurosensory hearing loss. Audiol Neurootol 2006;11:357-65.

3. Cohen S, Shoup A, Weisman MH, Harris J. Etanercept treatment for autoimmune inner ear disease: results of a pilot placebo-controlled study. Otol Neurotol 2005;26:903-7.

4. Street I, Jobanputra P, Proops DW. Etanercept, a tumour necrosis factor alpha receptor antagonist, and methotrexate in acute sensorineural hearing loss. J Laryngol Otol 2006;120:1064-6.

5. Giani T, Simonini G, Lunardi C, Puccetti A, De Martino M, Falcini F. Juvenile psoriatic arthritis and acquired sensorineural hearing loss in a teenager: is there an association? Clin Exp Rheumatol 2006;24:344-6.

6. Nores JM, Bonfils P. Rheumatoid arthritis and auto-immune hearing loss. A case study. Clin Rheumatol 1988;7:520-1.

J Rheumatol 2011;38:1; doi:10.3899/jrheum.100593 